\title{
Número de alelos XO em uma população de Melipona quadrifasciata anthidioides Lepeletier (Hymenoptera, Apidae, Meliponinae)
}

\author{
Davi S. Aidar ${ }^{1}$ \\ Warwick E. Kerr ${ }^{1}$
}

\begin{abstract}
Number of XO alleles in a population of Melipona quadrifasciata anthidioides Lepeletier (Hymenoptera, Apidae, Meliponinae). The number of xo alleles of a population of stingless bees can be estimated by observing the male proportion of the first brood comb produced by a new queen (about $40 \mathrm{~F} 1$ bees) and the total number of colonies. A proportion of $50 \%$ diploid males indicates insemination of the queen by a single male with some xo sex allele; $25 \%$ diploid male would indicate insemination by two males (one with some $\mathrm{xo}$ as the queen and another with different one). Diploidy was confirmed by cytology of the testis. The original population ( 78 colonies) of Ribeirão Preto, State S. Paulo, Brazil, had 8 xo sex alleles. From this population, 10 colonies were orphaned and taken to the Serra do Mar (Sea Mountains) at Espirito Santo State (1200 km far) in order that the virgin queen of each colony would cross with males of this region. Ten days after the nine hives (one was lost) were brought back to Ribeirão Preto. No one of them produced diploid males. New samples took from all the Meliponary revealed that the number of xo sex alleles to have increased to 17,3 . Than, this methodology can be used to increase the genetic variability of the stingless bees populations.

KEY WORDS. Melipona quadrifasciata anthidioides, colonies, population and alleles
\end{abstract}

MACKENSEN (1951) ao cruzar rainhas de Apis mellifera Linnaeus, 1758, com seus irmãos ou filhos, obteve 50\% de esterilidade. MACKENSEN (1955), encontrou 11 heteroalelos, xo ${ }^{1}$ a xo ${ }^{11}$, numa população de A. mellifera ligustica Spinola, 1806. Trabalhando com uma população de A. mellifera ibérica Ruttner, 1988, 12 alelos foram encontrados por LAIDLAW et al. (1956).

WOYKE (1963) observou que as operárias comiam as larvas de machos diplóides de A. mellifera, ocasionando 50\% de sobrevivência da cria. Criando esses machos diplóides em estufa, para que não fossem mortos pelas operárias, Woyke constatou que 50\% eram machos diplóides. Usando a mesma técnica CHAUD-NETO (1980a,b) conseguiu cruzá-los com rainhas normais e obter operárias triplóides.

O número de alelos sexuais numa população de abelhas africanizadas $(A$. mellifera) foi estudado por ADAMS et al. (1977). Este número foi estimado em 18,9 a partir da determinação do número de larvas de machos diplóides encontrados em 90 colônias de uma população de 500 colônias. PAGE et al. (1983) estudaram a distribuição dos alelos xo em populações fechadas de A. mellifera.

1) Instituto Nacional de Pesquisas da Amazônia. Avenida André Araújo 1756, Petrópolis, Caixa Postal 478, 69083-000 Manaus, Amazonas, Brasil. E-mail: aidar@argo.com.br 
KERR et al. (1978) sugerem que a determinação do sexo em abelhas ocorra em duas fases: a primeira fase, poucas horas após a postura e a segunda fase, no final da fase de pré-pupa, anteriormente à determinação de todos os discos imaginais, em que há uma interação entre os genes feminizantes aditivos (não compensados) e genes parcialmente não aditivos (compensados), determinadores de masculinidade.

KERR et al. (1996) sugere que o gene em questão seja curto (poucos nucleotídeos), visto que o número de heteroalelos encontrado foi entre 7 a 24. Em A. mellifera, MACKENSEN (1955), LAIDLAW et al. (1956) e ADAMS et al. (1977) encontraram 11, 12 e 18,4 alelos xo, respectivamente. KerR (1987) encontrou 20 alelos em Melipona compressipes fasciculata Smith, 1854. CARVALHO et al. (1995) encontraram de sete a 24 alelos em M. scutellaris Latreille, 1811.

As experiências de WOYKE (1976) demonstram que uma população com menos de seis alelos xo, não subsiste por muito tempo. KERR \& VENCOVSKY (1982) mostraram que para manter seis alelos precisa ter pelo menos 44 colônias. Abaixo disso, poderá ser extinta em cerca de 15 gerações (YOKOYAMA \& NEI 1979; KERR 1996). Em A. mellifera, as larvas de zangões com dois a três dias de vida são comidas pelas operárias (WOYKE 1963). Em M. quadrifascita Lepeletier, 1836, M. compressipes Smith, 1854 e M. scutellaris os machos diplóides chegam à fase adulta ou imago e então são mortos pelas operárias, bem como as rainhas que os produzem (CAMARGO 1982; KERR 1987; CARVALHO et al. 1995). Em regiões onde o número de colônias é baixo, elas tendem a desaparecer devido à formação de alelos xo em homozigose $\mathrm{e}$ isto ocorre com frequiência nas pequenas reservas de matas primárias que são conservadas (AIDAR 1996, 1997) e nos criadouros que tenham poucas colônias.

A distância de vôo das espécies de abelhas fornece dados que auxiliam o estudo da área de reprodução e de distribuição da população geneticamente ativa da região estudada. Em áreas onde os desmatamentos são freqüentes, esses dados permitem avaliar as possibilidades de homozigose dos alelos xo e de endogamia das espécies, bem como a disponibilidade de alimento próximo às colônias (ROUBIK 1989).

KERR (1959) fez experimentos empregando alimentador coletivo com xarope de açúcar deslocando-o a distâncias cada vez maiores para avaliar a distância de vôo de várias espécies e obteve os seguintes resultados: $M$. quadrifasciata coletou xarope até 2000 m; Trigona spinipes Fabricius, 1793, até 840 m; Plebeia droryana Friese, 1900, até $540 \mathrm{~m} ;$ T. amalthea Latreille, 1807, até $980 \mathrm{~m} ;$ A. mellifera até $2800 \mathrm{~m}$. KERR (1987) treinou M. compressipes fasciculata Smith 1854, a buscar xarope num alimentador coletivo e conseguiu afastar operárias à distância de $2470 \mathrm{~m}$.

As espécies A. cerana indica Fabricius, 1798 e A. florea Fabricius, 1787, voam até 120,700 e $400 \mathrm{~m}$, respectivamente (LINDAUER 1971). ROUBIK \& ALUJA (1983) mostraram que Cephalotrigona capitata Smith, 1854 volta de $2400 \mathrm{~m}$, respectivamente.

O raio de ação das castas reprodutivas (zangões e rainhas) pode determinar se a população está isolada reprodutivamente de outras populações e assim pode-se determinar o grau de consangüinidade dessa população e saber se ela está em equilíbrio e livre de ser extinta. Durante o vôo para acasalamento, as rainhas e zangões atingem distâncias maiores do que as operárias. WILLE (1983) cita que a distância de vôo de operárias de Tetragonisca angustula Latreille, 1911 é em torno de $600 \mathrm{~m}$. 


\section{MATERIAL E MÉTODOS}

\section{Seleção das colônias para cruzamento com populações do Espírito Santo}

De 78 colônias de $M$. quadrifasciata do Meliponário-A, localizado à Rua José da Silva, 868, Ribeirão Preto, São Paulo) foram selecionadas 10 para serem orfanadas e levadas a três diferentes meliponários do Espírito Santo, para que as novas rainhas acasalassem com machos não aparentados e de populações diferentes. As colônias selecionadas foram: 7, 15, 20, 25, 40, 53, 60, 62, 71 e 74. Estas colônias estão no meliponário a 10 anos e já foram divididas várias vezes, portanto compreendem a mesma população intercruzante. $\mathrm{O}$ critério de seleção das colônias foi a condição de terem no mínimo quatro favos de crias e potes de alimento de reserva suficiente para que as abelhas suportassem o estresse da orfandade, transporte e mudança de local. Destas colônias foram retiradas as rainhas fisogástricas dois dias antes de serem levadas para o Espírito Santo. As colônias foram alimentadas com Xarope-A ( $800 \mathrm{~g}$ de açúcar cristal $+1000 \mathrm{cc}$ de água $+5 \mathrm{ml}$ de Teragram- $\left.-\mathrm{M}^{\mathrm{r}}\right)$, em potes artificiais feitos com cera de abelhas africanizadas, um dia antes de serem fechadas e levadas para os locais de fecundação. Na noite anterior ao transporte, os orifícios de entrada das colméias foram fechados com tela metálica de malha fina que fôra presa com auxílio de fita adesiva.

\section{Distribuição das colônias nos Meliponários do Espírito Santo}

Chegando ao local de fecundação, municípios de São Paulo do Araçê e Domingos Martins, Espírito Santo, algumas colônias foram colocadas em cavaletes coletivos de ferro e outras foram dispostas conforme as condições locais. Nas matas desta região existem populações naturais de Melipona quadrifasciata.

As colméias permaneceram no Espírito Santo para fecundação durante 10 dias, de 2/IV/1997 a 12/IV/1997. Tempo estimado para que as rainhas virgens fossem aceitas pelas colônias e fecundadas por machos da região ao realizarem o vôo nupcial. Durante este período, as colônias foram alimentadas duas vezes em revisões rápidas. Após este período, as colméias foram devolvidas ao mesmo lugar que ocupavam, antes da viagem, no Meliponário-A, em Ribeirão Preto.

As colônias foram monitoradas até os primeiros favos de crias atingirem idade de 40 dias para contagem da proporção de machos e fêmeas pela observação dos gonóstilos presentes nas pupas dos machos.

\section{Colônias com rainhas acasaladas e divisão no Meliponário-A}

Após a contagem da proporção de machos e fêmeas, as colônias com rainhas acasaladas com machos do Espírito Santo foram manejadas até atingirem desenvolvimento para serem divididas (nota 7,0), de acordo com AIDAR (1996). Neste estágio, as rainhas fisogástricas foram retiradas das colônias e a nova rainha acasalada com machos do Meliponário-A. Suas crias foram monitoradas para avaliação da proporção de machos e fêmeas nos primeiros favos de crias. Daqueles favos que apresentaram proporção 1:1 de machos e fêmeas, algumas amostras de pupas foram submetidas à análises citogenéticas para confirmar a diploidia dos machos.

Depois de estar fechada, a colméia ficou em repouso durante 15 dias para que o processo de substituição de rainha não fosse interrompido. Após este período a colméia foi aberta para observação da presença de favos novos, o que indica a 
presença de rainha fisogástrica. Após 40 dias, os primeiros favos de crias foram avaliados quanto à proporção de machos e fêmeas para averiguação de possíveis endocruzamentos.

Utilizando o Método 1 de AIDAR (1996) para formação de colônias, novas colônias foram formadas com as rainhas acasaladas no Espírito Santo e mantidas na mesma área de reprodução do Meliponário-A para estimar o número de alelos xo da população.

\section{RESULTADOS E DISCUSSÃO}

\section{Alelos sexuais xo em população de $M$. quadrifasciata}

Antes da introdução das colônias acasaladas no Espírito Santo na população de $M$. quadrifasciata 15 colônias foram formadas e 3 colônias apresentaram machos diplóides (Tab. I). Desta forma, 8 alelos xo $(\mathrm{s}=0,58)$ foram estimados para a população original. Mostrando estabilidade da população com relação ao "Efeito Yokoyama e Nei" (YOKOYAMA \& NEI 1979), já que, o mínimo estabelecido por KERR \& VENCOVSKY (1982) são seis alelos para a população estar em equilíbrio.

Tabela I. Colônias de M. quadrifasciata formadas antes da introdução de colônias fecundadas no Espírito Santo.

\begin{tabular}{|c|c|c|c|c|c|c|c|}
\hline \multirow{2}{*}{$\begin{array}{l}\text { Número da } \\
\text { colônia }\end{array}$} & \multirow[t]{2}{*}{ Data inicial } & \multirow{2}{*}{$\begin{array}{l}\text { Início de } \\
\text { postura }\end{array}$} & \multirow{2}{*}{$\begin{array}{c}\text { Dias para } \\
\text { postura }\end{array}$} & \multirow{2}{*}{$\begin{array}{l}\text { Data de } \\
\text { contagem }\end{array}$} & \multirow{2}{*}{$\begin{array}{l}\text { Número de } \\
\text { fêmeas }\end{array}$} & \multicolumn{2}{|c|}{ Machos } \\
\hline & & & & & & Haplóide & Diplóide \\
\hline 56 & $26 / 09 / 1996$ & $10 / 11 / 1996$ & 45 & $23 / 12 / 1996$ & 19 & 0 & 0 \\
\hline 57 & $26 / 09 / 1996$ & $02 / 11 / 1996$ & 37 & $20 / 12 / 1996$ & 21 & 0 & 0 \\
\hline 59 & $26 / 09 / 1996$ & $11 / 11 / 1996$ & 46 & $20 / 12 / 1996$ & 23 & 0 & 0 \\
\hline 61 & $29 / 09 / 1996$ & $07 / 11 / 1996$ & 40 & $23 / 12 / 1996$ & 20 & 2 & 0 \\
\hline 62 & $29 / 09 / 1996$ & $30 / 10 / 1996$ & 32 & $20 / 12 / 1996$ & 19 & 0 & 16 \\
\hline 64 & $02 / 11 / 1996$ & $12 / 11 / 1996$ & 20 & $22 / 12 / 1996$ & 15 & 0 & 0 \\
\hline 65 & $19 / 02 / 1996$ & $10 / 03 / 1997$ & 19 & $23 / 04 / 1997$ & 15 & 2 & 0 \\
\hline 66 & $07 / 01 / 1997$ & $15 / 01 / 1997$ & 18 & $25 / 02 / 1997$ & 16 & 0 & 0 \\
\hline 67 & $02 / 11 / 1997$ & 03/12/1996 & 31 & $18 / 01 / 1997$ & 18 & 0 & 0 \\
\hline 69 & $20 / 12 / 1996$ & $10 / 01 / 1997$ & 21 & $25 / 02 / 1997$ & 22 & 0 & 0 \\
\hline 70 & $04 / 11 / 1996$ & $28 / 11 / 1996$ & 24 & $12 / 01 / 1997$ & 17 & 1 & 0 \\
\hline 72 & $06 / 11 / 1996$ & $06 / 12 / 1996$ & 30 & $10 / 01 / 1997$ & 16 & 0 & 15 \\
\hline 73 & $07 / 10 / 1997$ & $15 / 02 / 1997$ & 38 & $25 / 03 / 1997$ & 18 & 0 & 0 \\
\hline 76 & $16 / 01 / 1997$ & $05 / 02 / 1997$ & 20 & $25 / 03 / 1997$ & 27 & 0 & 29 \\
\hline 77 & $18 / 02 / 1997$ & $04 / 03 / 1997$ & 14 & $14 / 04 / 1997$ & 21 & 0 & 0 \\
\hline$N=15$ & $\mathrm{H}=3$ & $n=8$ & $S=3,36$ & & & & \\
\hline
\end{tabular}

(N) número total de colméias experimentais; $(H)$ número de colméias experimentais com $50 \%$ de machos diplóides; (n) número de alelos xo; (S) erro padrão.

Após a introdução de nove colônias contendo rainhas acasaladas com zangões de populações do Espírito Santo (Tab. II), 25 colônias filhas foram formadas e dois apresentaram machos diplóides (Tab. III), indicando que o número de alelos xo subiu para 17,33 ( $\mathrm{s}=1,25)$.

Nesta tabela visualiza-se também, que a média de dias entre a orfanação e o início da postura da rainha foi de 19,7 dias $(\mathrm{s}=4,85)$ com amplitude de 14 a 46 dias.

As colônias acasaladas com machos das populações do Espírito Santo não produziram machos diplóides e em apenas uma a rainha não realizou postura devido ao ataque de forídeos, enfraquecendo-a acentuadamente e ficando sem condições 
de recuperação. Esta colônia foi considerada morta para o experimento em questão. Porém, seus elementos foram empregados na formação de outras colônias. Sendo assim, 90\% das colônias apresentaram resultados positivos com relação ao acasalamento fora do Meliponário-A (Tab. II).

Tabela II. Colônias de $M$. quadrifasciata do Meliponário-A orfanadas e levadas ao Espírito Santo. (N1) Nota da colônia no momento da orfanação; (N2) nota da colônia no momento de início de postura; (N3) nota da colônia no momento da contagem da proporção dos sexos.

\begin{tabular}{|c|c|c|c|c|c|c|c|c|c|c|}
\hline \multirow{2}{*}{$\begin{array}{l}\text { Número } \\
\text { da colônia }\end{array}$} & \multirow{2}{*}{$\begin{array}{l}\text { Data de } \\
\text { a orfanação }\end{array}$} & \multirow[t]{2}{*}{ N1 } & \multirow{2}{*}{$\begin{array}{l}\text { Inicio de } \\
\text { postura }\end{array}$} & \multirow{2}{*}{$\begin{array}{c}\text { Dias para } \\
\text { postura }\end{array}$} & \multirow[t]{2}{*}{ N2 } & \multirow{2}{*}{$\begin{array}{l}\text { Data de } \\
\text { contagem }\end{array}$} & \multirow[t]{2}{*}{ N3 } & \multirow{2}{*}{$\begin{array}{l}\text { Número } \\
\text { de fêmeas }\end{array}$} & \multicolumn{2}{|c|}{ Machos } \\
\hline & & & & & & & & & Haplóide & Diplóide \\
\hline 7 & $29 / 03 / 1997$ & 5,3 & $16 / 04 / 1997$ & 18 & 3,9 & $22 / 05 / 1997$ & 5,3 & 30 & 0 & 0 \\
\hline 15 & $29 / 03 / 1997$ & 5,5 & $17 / 04 / 1997$ & 19 & 4,0 & $22 / 05 / 1997$ & 6,0 & 31 & 0 & 0 \\
\hline 20 & $29 / 03 / 1997$ & 6,0 & $17 / 04 / 1997$ & 19 & 5,0 & $25 / 05 / 1997$ & 5,8 & 28 & 0 & 0 \\
\hline 25 & $29 / 03 / 1997$ & 5,0 & $18 / 04 / 1997$ & 20 & 4,0 & $26 / 05 / 1997$ & 6,0 & 27 & 0 & 0 \\
\hline 40 & $29 / 03 / 1997$ & 6,0 & $19 / 04 / 1997$ & 21 & 4,5 & $22 / 05 / 1997$ & 5,3 & 19 & 0 & 0 \\
\hline 53 & $29 / 03 / 1997$ & 5,0 & $30 / 04 / 1997$ & 32 & 2,8 & $05 / 06 / 1997$ & 4,0 & 32 & 0 & 0 \\
\hline 60 & $29 / 03 / 1997$ & 4,2 & $19 / 04 / 1997$ & 21 & 4,0 & $22 / 05 / 1997$ & 4,8 & 35 & 0 & 0 \\
\hline 62 & $29 / 03 / 1997$ & 4,2 & $15 / 04 / 1997$ & 17 & 4,0 & $22 / 05 / 1997$ & 4,5 & 26 & 0 & 0 \\
\hline 71 & $29 / 03 / 1997$ & 5,0 & $12 / 04 / 1997$ & 14 & 5,5 & $22 / 05 / 1997$ & 5,8 & 29 & 0 & 0 \\
\hline 74 & $29 / 03 / 1997$ & 5,5 & $14 / 04 / 1997$ & 16 & 5,0 & $22 / 05 / 1997$ & 6,0 & 24 & 0 & 0 \\
\hline
\end{tabular}

Tabela III. Colônias de M. quadrifasciata formadas após a introdução das colônias do Espírito Santo.

\begin{tabular}{|c|c|c|c|c|c|c|c|}
\hline \multirow{2}{*}{$\begin{array}{l}\text { Número da } \\
\text { colônia }\end{array}$} & \multirow{2}{*}{$\begin{array}{l}\text { Data inicial ou } \\
\text { orfanação }\end{array}$} & \multirow{2}{*}{$\begin{array}{l}\text { Inicio de } \\
\text { postura }\end{array}$} & \multirow{2}{*}{$\begin{array}{c}\text { Dias para } \\
\text { postura }\end{array}$} & \multirow{2}{*}{$\begin{array}{c}\text { Data de } \\
\text { contagem }\end{array}$} & \multirow{2}{*}{$\begin{array}{l}\text { Número de } \\
\text { fêmeas }\end{array}$} & \multicolumn{2}{|c|}{ Machos } \\
\hline & & & & & & Haplóide & Diplóide \\
\hline 3 & 20/03/1998 & $10 / 04 / 1998$ & 21 & $21 / 05 / 1998$ & 18 & 1 & 0 \\
\hline 9 & $17 / 04 / 1998$ & 20/05/1998 & 33 & $30 / 06 / 1998$ & 21 & 0 & 0 \\
\hline $15(E S)$ orf. & $31 / 01 / 1998$ & $22 / 02 / 1998$ & 22 & $30 / 03 / 1998$ & 23 & 0 & 0 \\
\hline 20 (ES) orf. & $27 / 03 / 1998$ & $08 / 04 / 1998$ & 12 & $20 / 05 / 1998$ & 17 & 0 & 0 \\
\hline 25(ES) orf. & 05/09/1997 & $15 / 09 / 1997$ & 10 & $24 / 10 / 1997$ & 22 & 0 & 0 \\
\hline 30 & $17 / 03 / 1998$ & $15 / 04 / 1998$ & 29 & 29/05/1998 & 23 & 0 & 0 \\
\hline 40 (ES) orf. & 05/09/1997 & $25 / 09 / 1997$ & 20 & 29/10/1997 & 24 & 0 & 0 \\
\hline $43(E S)$ orf. & $22 / 04 / 1998$ & $30 / 04 / 1998$ & 8 & $13 / 06 / 1998$ & 19 & 2 & 0 \\
\hline 51 & $26 / 10 / 1997$ & $10 / 11 / 1997$ & 15 & $15 / 12 / 1997$ & 20 & 0 & 0 \\
\hline $71(E S)$ orf. & $17 / 04 / 1998$ & $28 / 04 / 1998$ & 11 & $12 / 06 / 1998$ & 26 & 0 & 0 \\
\hline $74(E S)$ orf. & 05/09/1997 & $17 / 09 / 1997$ & 12 & 20/10/1997 & 20 & 0 & 19 \\
\hline $60(E S)$ orf. & $02 / 04 / 1998$ & $21 / 04 / 1998$ & 19 & 05/06/1998 & 21 & 3 & 0 \\
\hline $62(E S)$ orf. & $01 / 10 / 1997$ & $15 / 10 / 19997$ & 14 & $24 / 11 / 1997$ & 23 & 0 & 0 \\
\hline 80 & $10 / 01 / 1998$ & $29 / 01 / 1998$ & 19 & 10/03/1998 & 20 & 0 & 18 \\
\hline 85 & 10/01/1998 & 28/01/1998 & 18 & $12 / 03 / 1998$ & 26 & 2 & 0 \\
\hline 88 & $10 / 11 / 1997$ & $28 / 11 / 1997$ & 18 & 13/01/1998 & 29 & 0 & 0 \\
\hline 89 & $27 / 10 / 1997$ & $03 / 12 / 1997$ & 37 & 06/01/1998 & 27 & 0 & 0 \\
\hline 90 & 07/10/1997 & $27 / 10 / 1997$ & 20 & $01 / 12 / 1997$ & 18 & 0 & 0 \\
\hline 91 & 05/10/1997 & $23 / 10 / 1997$ & 18 & $13 / 12 / 1997$ & 22 & 1 & 0 \\
\hline 92 & $20 / 11 / 1997$ & $11 / 12 / 1997$ & 21 & $13 / 01 / 1998$ & 24 & 0 & 0 \\
\hline 93 & $30 / 10 / 1997$ & $05 / 12 / 1997$ & 36 & 13/01/1998 & 26 & 1 & 0 \\
\hline 95 & $30 / 10 / 1997$ & $02 / 12 / 1997$ & 33 & 13/0i/1997 & 18 & 0 & 0 \\
\hline 96 & $27 / 11 / 1997$ & $12 / 01 / 1998$ & 46 & $13 / 02 / 1998$ & 25 & 0 & 0 \\
\hline 98 & $12 / 01 / 1998$ & $17 / 02 / 1998$ & 36 & $28 / 03 / 1998$ & 21 & 0 & 0 \\
\hline 99 & 06/03/1998 & $30 / 03 / 198$ & 24 & $10 / 05 / 1998$ & 16 & 0 & 0 \\
\hline$n=17,33$ & $\mathrm{H}=2$ & $N=25$ & $S=9,23$ & & & & \\
\hline
\end{tabular}

(N) número total de colméias experimentais; $(H)$ número de colméias experimentais com $50 \%$ de machos diplóides; (n) número de alelos xo; (S) erro padrão. 
Os dados demonstram que para a manutenção de meliponários experimentais ou comerciais deve-se manter a variabilidade genética da população introduzindo novas rainhas ou colônias com rainhas acasaladas em populações diferentes para evitar que o número de alelos xo na população fique abaixo de seis.

As rainhas virgens de $M$. quadrifasciata das colônias formadas e que tiveram suas rainhas retiradas demoraram 22,5 $(\mathrm{s}=2,12)$ e $18,0(\mathrm{~s}=5,65)$ dias para fecundar e iniciar postura, respectivamente (Tab. IV). No primeiro caso, a colônia formada passa por um período de reorganização (AIDAR 1996) e estruturação dos elementos que a compõem para depois iniciar os trabalhos normais de coleta de alimento no campo e aceitação de uma rainha virgem para efetuar o vôo nupcial e iniciar postura. Por outro lado, quando a colônia não é iniciada experimentalmente mas apenas sua rainha removida, esta já se apresenta estruturada e organizada, pronta para aceitação de uma nova rainha. Isto pode explicar o menor período que as colônias sem rainhas levam para apresentarem postura da nova rainha fisogástrica.

Tabela IV. Tempo que as colônias formadas e orfanadas demoraram para formarem rainha fisogástrica e iniciarem postura.

\begin{tabular}{|c|c|c|c|c|}
\hline Colônias formada & & Dias para postura & Colônias orfanadas & Dias para postura \\
\hline & 3 & 21 & $15(E S)$ orf. & 22 \\
\hline & 9 & 33 & 20 (ES) orf. & 12 \\
\hline & 30 & 29 & 25 (ES) orf. & 10 \\
\hline & 51 & 15 & 40(ES) orf. & 20 \\
\hline & 56 & 45 & $43(E S)$ orf. & 8 \\
\hline & 57 & 37 & $71(\mathrm{ES})$ orf. & 11 \\
\hline & 59 & 46 & $74(E S)$ orf. & 12 \\
\hline & 61 & 40 & $60(E S)$ orf. & 19 \\
\hline & 62 & 32 & $62(\mathrm{ES})$ orf. & 14 \\
\hline & 64 & 20 & & \\
\hline & 65 & 19 & & \\
\hline & 66 & 18 & & \\
\hline & 67 & 31 & & \\
\hline & 69 & 21 & & \\
\hline & 70 & 24 & & \\
\hline & 72 & 30 & & \\
\hline & 73 & 38 & & \\
\hline & 76 & 20 & & \\
\hline & 77 & 14 & & \\
\hline & 80 & 19 & & \\
\hline & 85 & 18 & & \\
\hline & 38 & 18 & & \\
\hline & 39 & 37 & & \\
\hline & 90 & 20 & & \\
\hline & 91 & 18 & & \\
\hline & 92 & 21 & & \\
\hline & 93 & 36 & & \\
\hline & 95 & 33 & & \\
\hline & 96 & 46 & & \\
\hline & 98 & 36 & & \\
\hline & 99 & 24 & & \\
\hline Total (n) & 31 & - & 9 & - \\
\hline Média & - & 22,5 & - & 18 \\
\hline Desvio padrão & - & 2,12 & - & 5,65 \\
\hline
\end{tabular}

Mesmo a colônia 74, após ter sido orfanada no Meliponário-A, que apresentou $50 \%$ de machos diplóides, em nenhum momento apresentou sinais de enfraque-

Revta bras. Zool. 18 (4): 1237 - 1244, 2001 
cimento. Permaneceu sempre forte até a troca de rainha. Em condições naturais, no campo sem estresse de revisões, este fato pode mostrar que uma colônia de meliponíneo supera com facilidade a primeira troca de rainha. Mas a colônia morre se estiver fraca ou se os acasalamentos com xo iguais se repetirem.

Até 17/4/97,70\% das colônias tinham rainha fisogástrica e nenhuma delas apresentou proporção de 1:1 entre machos e fêmeas. Todas foram colônias vigorosas e tiveram desenvolvimento mais acelerado quando comparadas com as colônias do Meliponário-A. A maioria das colônias do Meliponário-A são parentes entre si e as colônias acasaladas no Espírito Santo têm maior variabilidade genética porque suas rainhas acasalaram-se com zangões de populações com maior variabilidade genética.

\section{Diferenças entre as colônias do Espírito Santo e do Meliponário-A}

Nas populações de M. quadrifasciata de Ribeirão Preto e do Espírito Santo, algumas diferenças entre as colônias foram notadas mediante observação direta das colônias. Com relação à cera, as colônias do Espírito Santo apresentaram cera mais escura, mais maleável (elástica) e o aroma mais acentuado (perfumada). As operárias das colônias do Espírito Santo são maiores do que as operárias das colônias do Meliponário-A e que das operárias de colônias da região sul do país. O número de abelhas das colônias foram relativamente iguais. Os favos de cria são maiores nas colônias do Espírito Santo.

Também foi observado que essas diferenças não são devidas às influências ambientais porque as colônias do Espírito Santo trazidas para Ribeirão Preto continuaram apresentando as mesmas características depois de alguns meses, mesmo estando em colméias semelhantes e mesmo ambiente das colônias do Meliponário-A.

\section{Tempo para as rainhas das colônias orfanadas iniciarem postura}

As colônias orfanadas iniciaram postura mais cedo do que as colônias formadas. O tempo que a colônia recém formada leva para ter seus elementos ( $\mathrm{I}$, FN, P, C, O, etc.) organizados proporcionando condições de produção de células de crias e manutenção da temperatura das mesmas é maior quando comparado às colônias orfanadas, que têm todos os elementos organizados e estão prontas a aceitarem rainha virgem para posterior vôo nupcial e iniciar postura.

\section{REFERÊNCIAS BIBLIOGRÁFICAS}

Adams, J.; E.D. Rothman; W.E. KerR \& Z.L. Paulino. 1977. Estimation of the number of sex alleles and queen mating from diploid male frequencies in a population of Apis mellifera L. Genetics 86: 583-596.

AIDAR, D.S. 1997. Meliponicultura e Ecossistema: Preservação, Formação de Colônias, Manejo e Alimentação de Meliponíneos (Hymenoptera, Apidae, Meliponinae). Ann. Simpósio Paranaense de Apicultura, Guarapuava, 12: 48-55.

1996. A Mandaçaia: Biologia de abelhas, manejo e multiplicação artificial de Melipona quadrifasciata Lepeletier, 1836, (Hymenoptera, Apidae, Meliponinae). Braz. Jour. Genetics, Sér. Monogr. 4: 1 - 103.

CAMARGO, C.A. 1982. Control of production of Melipona quadrifasciata diploid males by workers bees (Hym., Apidae). Proc. $9^{\text {th }}$ Congress IUSSI, Boulder, p. 248-249. 
Carvalho, G.A.; W.E. KerR; V.A. Nascimento. 1995. Sex determination in bees XXXIII: Decrease of xo heteroalleles in finite population of Melipona scutellaris (Apidae, Meliponini). Braz. Jour. Genetics 18 (1): 13-16.

Chaud-Neto, J. 1980a. Estudos biológicos com rainhas triplóides de Apis mellifera. Ci. e Cult. 32 (5): 611-615.

— 1980b. Estudos biológicos com rainhas triplóides de Apis mellifera. I. Produção de ovos abortivos por rainhas virgens. Ci. Cult. 32 (4):483-486.

KERR, W.E. 1959. Bionomy of meliponids-VI: Aspects of food gathering and processing in some stingless bees. In: Symposium on Foos Gathering Behavior of Hymenoptera. Ithaca, Cornell Univ., p. 24-31.

- 1987. Sex determination in bees. XXI. Number of xo-heteroelleles in a natural population of Melipona compressipes fasciculata (Apidae). Insectes Sociaux 34: 274-279.

KeRR, W.E; G.A. CARVAlho \& V.A. NASCIMENTO. 1996. Abelha uruçu: biologia, manejo e conservação. Belo Horizonte, Ed. Fundação Acangaú, 256p.

KeRR, W.E; R. Cunha; J.F. PISANI. 1978. Genética de determinação do sexo XII. Aplicação de métodos numéricos para agrupar sexos e castas de Melipona quadrifasciata anthidioides Lep. (Apidae). Rev. Brasil. Biol. 38 (2): 319-394.

KeRR, W.E. \& R. VENCOVSKY. 1982. Melhoramento genético em abelhas I. Efeito do número de colônias sobre o melhoramento. Braz. Jour. Genetics 5: 279-285.

LAIDLAW, H.H.; F.P. GOMES \& W.E. KERR. 1956. Estimation of the number of lethal alleles in a panmitic population of Apis mellifera L. Genetics 44: 179-188.

Lindauer, M. 1971. Comunication Among the Social Bees. Cambrige, Massachusetts, Harvard Univ. Press.

MACKensen, O. 1951. Viability and sex determination in the honey bee (Apis mellifera L.). Genetics 36: $500-509$.

— 1955. Further studies on a lethal series in the honeybee. Jour. Hered. 46: 72-74.

PAGE JR., R.E.; H.H. LAIDLAW \& E.H. ERICKSON. 1983. Closed population honey bee breeding. 3. The distribution of sex alleles with gyne supersedure. Jour. Apic. Res. 22: 184-190.

RoubIK, D.W. 1989. Ecology and Natural History of Tropical Bees. Cambridge, Univ. Press, 514p.

RoubiK, D.W. \& M. Aluja. 1983. Flyght ranges of Melipona and Trigona in tropical forest. Jour. Kansas Ent. Soc. 56 (2): 217-222.

Wille, A. 1983. Biology of the stingless bees. Annu. Rev. Entomol. 28: 41.

WOYKE, J. 1976. Population genetc studies on sex alleles in the honeybee using the exemple of Kangaroo Island Bee Santuary. Jour. Apic. Res. 15: 105-123.

- 1963. What happens to diploid drone larvae in a honeybee colony. Jour. Apic. Res. 2: 73-76.

Yokoyama, S. \& M. Nei. 1979. Population dynamics of sex-determining alleles in honey bees and self-incompatibility alleles in plants. Genetics 91: 609-626.

Recebido em 21.Il.2001; aceito em 26.X.2001. 